dangerous assault on the brain ECT comes in, too, for criticism on political grounds. Its use is said to be an assault on the patient, on his individuality, on his right to hold heterodox views and to be allowed to do his own thing. Furthermore, it attracts odium as one of the measures used by an authoritarian society to coerce into conformity those who choose to be different. This may well be a valid criticism of its use in some societies where psychiatry is misused as a weapon of political oppression, but elsewhere ECT is much more likely to be misused from clinical error-withheld from those who need it, and given to those to whom it is harmful.

\footnotetext{
${ }^{1}$ D'Agostino, A M, American fournal of Psychiatry, 1975, 132, 629.

${ }^{2}$ Hippius, H, in Depressive Illness: Diagnosis, Assessment, Treatment, ed P Kielholz. Bern, Hans Huber, 1972.

${ }^{3}$ Dally, P J, in The Scientific Basis of Drug Therapy, ed John Marks and C M B Pare. Oxford, Pergamon Press, 1965.

${ }^{4}$ Shepherd, M, Lader, M, and Rodnight, R, Clinical Psychopharmacology. London, English University Press, 1968.

5 Mayer-Gross, W, Slater, E, and Roth, M, Clinical Psychiatry, 3rd edn. London, Bailliere Tindall and Cassell, 1969.

${ }^{6}$ Pinter, H, The Caretaker, 2nd edn. London, Methuen, 1962
}

\section{Confirming the diagnosis of coeliac disease}

At some time most paediatricians and physicians will have inherited a patient labelled as having "coeliac disease" who is healthy and taking a gluten-free diet and yet whose initial diagnosis was made on somewhat flimsy evidence. An established diagnosis of coeliac disease implies a gluten-free diet for life, so that strict criteria for the diagnosis are necessary; this does not mean merely a single jejunal biopsy. In early life other conditions such as cows' milk protein intolerance ${ }^{1}$ and secondary malabsorption after gastroenteritis ${ }^{2}$ may produce similar clinical, laboratory, and histological findings to those of coeliac disease. Because of this, the European Society for Paediatric Gastroenterology has adopted diagnostic criteria which require at least three jejunal biopsies-one before treatment, one after 6-12 months' treatment with a gluten-free diet to establish histological recovery, and a final one after reintroduction of gluten at the end of two years of the diet to demonstrate permanent histological susceptibility to gluten.

However justified this ideal method of diagnosis may be, it is certain that for many years doctors will continue to encounter patients in whom the diagnosis of coeliac disease has been made on less precise grounds, and sometimes on grounds that are clearly suspect. Someone with coeliac disease may develop clinical, and should develop histological, relapse after the reintroduction of gluten. ${ }^{3}$ There has been considerable variation in the sort of gluten challenge that has been used to confirm the diagnosis in someone previously receiving a gluten-free diet. Some physicians have merely reintroduced a normal diet, while others have given measured amounts of gluten according to body size for various periods of time. Similarly, there has been variation in the selection of criteria for identifying relapse after reintroduction of gluten and some lack of standardisation of the procedures. Recent work from Birmingham ${ }^{4}$ may help to remedy these variations. Rolles $\mathrm{et}^{\mathrm{al}}{ }^{4}$ used the one-hour blood xylose test on 16 children, all of whom had been diagnosed as having coeliac disease in the first year of life. They had been treated with a gluten-free diet for up to five years before being given a standard gluten challenge ( $10 \mathrm{~g}$ gluten twice a day). Xylose malabsorption was demonstrated in all except one child within 28 days. The remaining patient had a persistently normal absorption, and the jejunal biopsy appearances remained normal after 18 months of gluten; the child was considered not to have coeliac disease.

The one-hour xylose test has had a controversial life. In 1973 it was hailed as a simple, effective screening test. ${ }^{5}$ It is certainly simple, requiring only one estimation of blood xylose after an oral dose of xylose given to the fasting patient. A normal one-hour xylose level was said to exclude coeliac disease if the patient was receiving gluten at the time of the test. Then workers in other centres failed to confirm its reliability. It seemed to be a test that only the specialised unit could use with confidence. Recently Littlewood ${ }^{6}$ has put the test into a better perspective: using it on a general paediatric ward and adopting less stringent criteria for xylose malabsorption (all coeliacs had a one-hour xylose below $30 \mathrm{mg} / \mathrm{dl}$ ) he found it to be a useful screening test.

The report from Birmingham of the usefulness of the test after gluten challenge for children previously diagnosed as having coeliac disease may be an important contribution. At the least it seems to provide a useful way of selecting the optimal time for the confirmatory biopsy. But the history of problems and controversy associated with the one-hour xylose test makes it important that confirmation of the Birmingham results should come from elsewhere.

\footnotetext{
1 Visakorpi, J K, and Immonen, P, Acta Paediatrica Scandinavica, 1967, 56, 49.

2 Burke, V, Kerry, K R, and Anderson, C M, Australian Paediatric fournal, $1965,1,147$

${ }^{3}$ Meeuwisse, G W, Acta Paediatrica Scandinavica, 1970, 59, 461.

${ }^{4}$ Rolles, C J, Anderson, C M, and McNeish, A S, Archives of Disease in Childhood, 1975, 50, 259.

${ }^{5}$ Rolles, C J, et al, Lancet, 1973, 2, 1043.

${ }^{6}$ Littlewood, J M, Archives of Disease in Childhood, 1975, 50, in press.
}

\section{Artificial insemination (donor)}

About $10 \%$ of the eight million married couples in these islands are involuntarily sterile. As a conservative estimate, in about $30 \%$ of these marriages the sterility is due to the husband; so there are approximately 250000 couples whose wish for a family is denied because of male infertility. Somebut increasingly few because of the high numbers of abortions and the reliability of modern contraceptives-can solve their problems by adoption. Some of these cases are treatable; if, however, the husband's total sperm count is under 1 million artificial insemination from a donor is at present the only way in which the wife can achieve pregnancy. Even a total count of 10 million only rarely results in pregnancy.

There is still resistance by many couples to this method of raising a family, and indeed it does require on the part of both husband and wife emotional maturity and a good understanding of each other's needs. Nevertheless, many couples would resort to artificial insemination from donors were it known that the facilities are easily available and ethically, legally, and morally acceptable. What the Government approves and pro- 
vides freely many willingly take; and the NHS has asked doctors in certain infertility centres to provide this service. Practical difficulties, however, have so far severely restricted its provision. These difficulties are in the main administrative. The secrecy that is absolutely essential (more so perhaps than in any other form of medical practice) is difficult to maintain. The woman who is being inseminated has to be able to lie up quietly for about half an hour after the insemination, and in centres with no day unit for the treatment of gynaecological cases the provision of a suitable couch or a bed brings its own problems, as does the finding of a nurse willing to help in such work on a permanent basis-it is no use asking temporary nurses to come into the clinic for this purpose. A semen bank is almost essential for inseminating large numbers of women, but again there are practical difficulties. The liquid nitrogen has to be delivered on the right day and the right person has to be in the unit to receive it and to ensure that the bank is properly sealed and that the temperature is kept at the correct very low level. Outside the NHS several doctors are providing such a service at relatively low fees, either privately or on a charitable or semi-charitable basis.

Donors must be free of communicable, inherited, and inheritable diseases, and each donor should match the husband's physical characteristics. When he does the children grow in the family to resemble the husband almost uncannily. The source of donors is somewhat controversial. Most are medical students or college graduates who expect to be paid, even if only a small sum; but it may be argued that this raises a precedent and that blood donors might not be willing to donate freely as they do at present. Even when medical students are willing to give their semen for nothing some deans of medical schools point out that they have given undertakings not to ask students voluntarily to take part in any procedures, be they experimental or therapeutic, for the benefit of patients. Students come to medical school to be taught, not to be used. Probably the best source is the husbands of women successfully treated in the infertility clinic; there is the added advantage that they are of proved fertility and their offspring can be seen to be free of obvious defect.

Different authorities have reported oddly different success results. Millet et al ${ }^{1}$ put the chance of success at about one in four. Donald Goss ${ }^{2}$ reported 51 conceptions in 41 patients, resulting in 43 live births out of 55 couples where donor insemination was accepted; the mean number of inseminations was $4 \cdot 2$.

In December 1972 the CIBA Foundation held a symposium on the legal, ethical, and moral aspects of donor artificial insemination. Theologians, lawyers, gynaecologists, and philosophers from five different countries participated. The conclusion" was that "The law has got to consider AID not in a prohibitory way and perhaps in a regulatory way so far as is required to make the technique acceptable to society." At present there is nothing in the law to make AID illegal, and the consensus of opinion at the symposium was that it was ethically and morally justified in suitable cases. All the same it is not possible to write out a prescription for artificial insemination on a prescription pad. It requires responsible assessment, excellent and expensive organisation, and above all tact, confidentiality, and absolute secrecy.

1 Millet, D, Jondet, M, and Necker, A, Actualités Gynecologıques, p 141 Paris, Masson, 1974.

2 Goss, D A, American fournal of Obstetrics and Gynecology, 1975, 122, 246.

${ }^{3}$ Wolstenholme, G E W, and Fitzsimons, W, eds, Law and Ethics of AID and Embryo Transfer, CIBA Foundation Symposium No 17. Amsterdam, Excerpta Medica, 1973.

\section{VIP and watery diarrhoea}

The watery diarrhoea syndrome or pancreatic cholera is a complication of functioning non-beta-cell tumours of the endocrine pancreas. First described by Verner and Morrison in $1958,{ }^{1}$ so far fewer than 100 cases have been recorded in published reports. The patients' main complaint is of chronic, profuse, watery diarrhoea, which leads to dehydration and hypokalaemia. This is accompanied by hypochlorhydria, hyperglycaemia, and attacks of flushing. For some time it has been thought that this syndrome was due to the excess production of a peptide hormone, similar to the excess secretion of gastrin by pancreatic tumours causing hyperchlorhydria in the Zollinger-Ellison syndrome. Yet none of the possible hormones-secretin, gastrin, glucagon, or gastric inhibitory peptide-had the right spectrum of properties to be the mediator of the syndrome.

In 1970 vasoactive intestinal peptide (VIP) was isolated from pig small intestine. ${ }^{2}$ Fharmacological studies have shown that VIP has many more properties than its name (given as the result of it first being assayed by its vasodilatory action) might imply. VIP strongly stimulates the intestinal secretion of water and electrolytes, ${ }^{3}$ inhibits gastric secretion, ${ }^{34}$ promotes glycogenesis and hyperglycaemia, ${ }^{5}$ and causes hypercalcaemia. ${ }^{6}$ It also has a secretin-like action on the pancreas, stimulating production of pancreatic juice.

Evidence that VIP is the mediator of the watery diarrhoea syndrome was produced by Bloom, Polak, and Pearse ${ }^{7}$ in 1973, when they used a specific radioimmunoassay to show raised plasma levels of VIP in four patients and established by immunofluorescent antisera and bioassay that pancreatic tumours in these patients contained VIP.

More recently, Said and Falcona ${ }^{8}$ have described their investigations of plasma VIP levels in a series of 30 patients with the watery diarrhoea syndrome. In four no tumour was found; 13 had a pancreatic islet cell adenoma, four islet cell hyperplasia, and one each a phaeochromocytoma and a ganglioneuroblastoma. The finding of six patients with bronchial carcinoma with this syndrome was of particular interest. The radioimmunoassay used was generally unable to detect VIP in the plasma of normal controls, though in 26 of the 28 patients in whom it was measured the plasma VIP levels were raised. In each of the 13 tumours that were assayed the VIP levels were high, the highest being in the phaeochromocytoma and the ganglioneuroblastoma. There was no relation between the VIP levels within the tumour and those in the plasma. A fall in plasma VIP levels was found in five patients in whom the diarrhoea ceased after medical or surgical treatment. Unexplained high plasma VIP levels were found in two out of 50 controls; Said and Falcona suggest that isolated raised plasma VIP levels should be interpreted with caution. Their quest for cases from centres in Europe and America has led to the discovery that VIP can be produced by various tumour types, whichas the authors suggest-may be united by their common ancestry in the neural crest.

Probably VIP estimations may be of increasing value in diagnosis; indeed, this radioimmunoassay may lead to an earlier discovery of pancreatic tumours, for in the past on average it was three years before the diagnosis was finally established in patients with this syndrome. ${ }^{9}$ It is, however, unlikely that its application to other aspects of gastrointestinal disease will share the clarity of the association shown and confirmed in the watery diarrhoea syndrome. But often 